\title{
Desempenho e características de carcaça de frangos de corte alimentados com rações contendo farelo da castanha de caju tratado ou não com antioxidante
}

\author{
Irani Ribeiro Vieira Lopes ${ }^{1}$, Maria de Fátima Freire Fuentes ${ }^{2}$, Ednardo Rodrigues Freitas ${ }^{2}$, \\ Roberto Batista da Silva ${ }^{3}$, Raffaella Castro Lima ${ }^{4}$, Roseane Madeira Bezerra ${ }^{4}$
}

${ }_{1}$ Programa de Doutorado Integrado em Zootecnia-PDIZ/CCA/UFC.

2 Departamento de Zootecnia-CCA/UFC.

${ }^{3}$ Curso de Pós-graduação em Zootecnia - DZ/CCA/UFC.

${ }^{4}$ Curso de graduação em Zootecnia - DZ/CCA/UFC.

RESUMO - O experimento foi realizado para avaliar a estabilidade oxidativa do farelo da castanha de caju (FCC) tratado ou não com antioxidante butil-hidroxitolueno (BHT) e armazenado por 35 dias e estudar o efeito de rações formuladas com esse ingrediente sobre o desempenho e as características de carcaça de frangos de corte. Um lote de $400 \mathrm{~kg}$ de FCC foi dividido em cinco partes. Uma parte foi armazenada sem a adição de antioxidante e as demais foram tratadas com 500 ppm de BHT nos dias 0, 7, 14 e 21 de armazenamento. A estabilidade oxidativa do FCC foi acompanhada pelos índices de acidez e de peroxidação, determinados semanalmente. No final do período de 35 dias de armazenamento, 15\% de FCC não tratado ou tratado com BHT foi usado na formulação de rações isonutritivas para frangos de corte. Foram utilizados 480 pintos machos de 1 dia, linhagem Ross, distribuídos em delineamento inteiramente casualizado, com 5 tratamentos e 8 repetições de 12 aves. O índice de acidez do FCC durante o período de armazenamento não variou, independentemente do uso de antioxidante, enquanto o índice de peróxidos do farelo com ou sem BHT aumentou com o tempo de armazenamento. O tratamento do FCC com antioxidantes não afetou o desempenho, as características de carcaça, o teor de umidade do fígado e os teores de umidade e extrato etéreo da gordura abdominal dos frangos de corte. Entretanto, o teor de extrato etéreo do fígado das aves alimentadas com a ração contendo FCC tratado com BHT no dia zero foi mais baixo que o daquelas alimentadas com a ração controle. O farelo de castanha de caju sem antioxidante armazenado por 35 dias, embora sofra processo de rancidez oxidativa, pode ser utilizado em níveis de até $15 \%$ na ração de frangos de corte, pois não afeta o desempenho e as características de carcaça.

Palavras-chave: BHT, conversão alimentar, ganho de peso, índice de peróxidos

\section{Performance and carcass characteristics of broilers fed diets containing cashew nut meal treated or not with antioxidant}

\begin{abstract}
This experiment was conducted to evaluate the oxidative stability of cashew nut meal (CNM) treated or not with butylated hydroxytoluene (BHT) at different storage times and the effect of diets containing this ingredient on the performance and carcass characteristics of broilers. A batch of $400 \mathrm{~kg}$ of freshly produced CNM was divided into five equal portions. One portion was stored with no antioxidant and the others were treated with 500 ppm of BHT at days zero, 7, 14 and 21. The oxidative stability of CNM was measured by the acidity index and peroxide index determined by weekly samplings of the CNM. At the end of the 35-day storage time, 15\% of CNM treated or not with BHT was used in the formulation of broiler diets. A feed trial was carried out with 480 day-old male Ross chicks. Birds were randomly distributed among the 5 treatments with 8 replications of 12 birds each. Acidity index of CNM did not vary, regardless of antioxidant use. However, PI values for CNM with or without BHT increased with storage time. Treatments did not affect broiler performance (feed intake, weight gain and feed conversion), carcass characteristics (carcass yield, breast yield and percentage of liver and abdominal fat), liver moisture, ether extract and abdominal fat moisture content. The ether extract content of the liver, nevertheless, was lower in birds that received diet containing CNM treated with BHT at day zero of storage than those from the control treatment. CNM stored for 35 days without BHT suffered a lipid peroxidation process. However, the use of $15 \%$ of this ingredient in diets did not affect broiler performance and carcass characteristics.
\end{abstract}

Key Words: BHT, feed conversion, peroxide index, weigh gain 


\section{Introdução}

A busca de alimentos alternativos que possam suprir as necessidades das aves e reduzir os custos de produção sem comprometer o desempenho é fundamental para a indústria avícola, principalmente em criatórios de pequeno e médio porte.

A amêndoa da castanha de caju é encontrada facilmente no Nordeste do País e, durante o processamento, estima-se que 2 a $5 \%$ das castanhas sejam desperdiçadas por serem impróprias para o consumo humano, constituindo-se refugo que, transformado em farelo, pode ser utilizado na alimentação animal (Pimentel, 1992).

Por sua riqueza em lipídios, constituídos na maior parte por ácidos graxos insaturados, o farelo da castanha de caju (FCC) está propenso a rancidez oxidativa, processo que resulta na destruição de certos nutrientes, como ácidos graxos essenciais, proteínas, vitaminas lipossolúveis e carotenoides (Leeson \& Summers, 2001). Nos casos em que esta destruição é mais severa, as aves podem apresentar doenças carenciais, como encefalomalácia, diástase exsudativa, distrofia muscular, necrose tecidual em vários órgãos, além de redução na fertilidade e na eclodibilidade (Cabel et al., 1988).

Para neutralizar os efeitos deletérios dos radicais livres, é comum a utilização de antioxidantes, cuja função é preservar o alimento, retardando a sua oxidação. A adição de antioxidante aos ingredientes ou às rações, além de evitar gastos com a suplementação de nutrientes especializados destruídos durante o processo de peroxidação, também assegura ao nutricionista que as rações formuladas estejam de acordo com as exigências estabelecidas e que a maior porcentagem dos nutrientes da ração permaneça disponível para o animal (Fischer et al., 2005). Entretanto, o custo adicional com o tratamento do FCC com antioxidantes logo após o seu beneficiamento pode ser desfavorável à adoção dessa prática.

Os objetivos nesta pesquisa foram avaliar a estabilidade oxidativa do farelo de castanha de caju (FCC) tratado ou não com antioxidante em diversos períodos de tempo e armazenado por 35 dias e analisar o efeito do uso de rações contendo esse ingrediente sobre o desempenho, as características de carcaça e os teores de umidade e extrato etéreo do fígado e da gordura abdominal de frangos de corte.

\section{Material e Métodos}

Um lote de $400 \mathrm{~kg}$ de farelo de castanha de caju (FCC) foi adquirido logo após o beneficiamento e, ao chegar à fábrica de ração, foi triturado e homogeneizado, retirando-se amostras para a análise da composição química e dos índices de acidez e de peroxidação. Em seguida, o lote foi dividido em cinco porções de 80 kg: uma porção foi armazenada sem adição de antioxidante butil hidroxitolueno (BHT) e as demais, tratadas com $40 \mathrm{~g}$ de BHT, equivalente a 500 ppm, no dia zero e aos 7, 14 e 21 dias de armazenamento. Os sublotes de FCC foram acondicionados em sacos de ráfia e armazenados sobre tablado de madeira, em local coberto, seco, bem ventilado e fora do alcance da luz, durante 35 dias.

Semanalmente, durante o armazenamento, foram coletadas amostras de FCC tratado ou não com antioxidante com o objetivo de monitorar os índices de acides e peroxidação do produto, determinados de acordo com as metodologias descritas na AOAC (1990).

Decorrido o tempo de armazenagem, os farelos foram utilizados para preparar as rações dos frangos de corte.

No ensaio de desempenho, foram utilizados 480 pintos machos de 1 dia de idade, da linhagem "Ross", distribuídos em delineamento inteiramente casualizado com cinco tratamentos e oito repetições de 12 aves cada.

Os valores de exigências nutricionais e de composição dos alimentos usados para formular as rações experimentais foram baseados nas tabelas de Rostagno et al. (2000). Para o FCC, foram utilizados os dados descritos pela EMBRAPA (1991), os quais foram ajustados de acordo com as análises de composição química realizadas conforme a metodologia descrita por Silva \& Queiroz (2002). Segundo estas análises, o FCC apresentou 94,74\% de matéria seca, 22,39\% de proteína bruta, 47,01\% de extrato etéreo e $6.412 \mathrm{kcal}$ de energia bruta $/ \mathrm{kg}$.

Os tratamentos, para cada fase de criação (inicial, crescimento e final), consistiram de cinco rações isonutritivas (Tabela 1) contendo FCC sem adição de BHT (s/BHT); FCC com adição de BHT no dia zero (BHT/0); FCC com adição de BHT 7 dias após o armazenamento (BHT/7); FCC com adição de BHT 14 dias após o armazenamento (BHT/14); e FCC com adição de BHT 21 dias após o armazenamento (BHT/21).

Durante o período experimental, as aves receberam ração e água à vontade. A temperatura e a umidade relativa média do ar foram registradas duas vezes ao dia.

No início do experimento e aos 21 e 42 dias de idade, a ração fornecida e as sobras foram pesadas para determinar a quantidade de alimento consumido. Nesses mesmos períodos, também se procedeu à pesagem das aves de cada parcela para que o ganho de peso médio da parcela fosse calculado. A partir dos dados de consumo de ração e de ganho de peso dos frangos, foi calculada a conversão alimentar. 
Tabela 2 - Índices de acidez e de peróxidos do farelo de castanha de caju, tratado ou não com BHT, em diferentes tempos de armazenamento

\begin{tabular}{|c|c|c|c|c|c|c|}
\hline & \multicolumn{6}{|c|}{ Tempo de armazenamento (dias) } \\
\hline & 0 & 7 & 14 & 21 & 28 & 35 \\
\hline & \multicolumn{6}{|c|}{ Índice de acidez (meq/100 g) } \\
\hline Sem BHT & 7,744 & 7,996 & 6,688 & 7,853 & 6,683 & 6,469 \\
\hline Com adição de BHT no dia zero & 7,744 & 7,743 & 6,333 & 7,498 & 6,887 & 6,370 \\
\hline Com adição de BHT no dia 7 & 7,744 & 7,996 & 6,991 & 7,499 & 7,090 & 6,475 \\
\hline Com adição de BHT no dia 14 & 7,744 & 7,996 & 6,688 & 8,309 & 7,390 & 6,482 \\
\hline Com adição de BHT no dia 21 & \multicolumn{6}{|c|}{ Índice de peroxidação (meq/kg) } \\
\hline Sem BHT & 0,924 & 0,767 & 0,987 & 1,617 & 1,944 & 2,255 \\
\hline Com adição de BHT no dia 0 & 0,924 & 0,572 & 0,846 & 1,541 & 1,538 & 1,956 \\
\hline Com adição de BHT no dia 7 & 0,924 & 0,767 & 1,609 & 1,617 & 1,487 & 1,697 \\
\hline Com adição de BHT no dia 14 & 0,924 & 0,767 & 0,987 & 1,691 & 1,578 & 1,947 \\
\hline Com adição de BHT no dia 21 & 0,924 & 0,767 & 0,987 & 1,617 & 1,621 & 2,013 \\
\hline
\end{tabular}

BHT = butil-hidroxitolueno

O maior índice de peróxidos obtido nesta pesquisa (2,255 meq/ kg de FCC) foi inferior aos relatados na literatura. O valor máximo de peroxidação encontrado por Silva et al. (1990) foi de 113,00 meq/kg no farelo de arroz não tratado com antioxidante (BHT ou ETQ) e armazenado por 11 meses, enquanto Racanicci et al. (2000) observaram índice de peroxidação de 69,23 meq/kg quando a farinha de carne e ossos foi armazenada durante 10 semanas sem BHT. Por sua vez, Fischer et al. (2005) obtiveram o maior nível de peroxidação, aproximadamente $10,00 \mathrm{meq} / \mathrm{kg}$ na quarta semana de armazenagem do milho triturado e não tratado com ETQ.

O baixo nível de peróxidos determinado no FCC após 35 dias de armazenamento, com ou sem antioxidante, pode ser decorrente da composição de ácidos graxos desse alimento. Embora o FCC apresente elevada porcentagem de ácidos graxos insaturados (82,74\%), predominam o ácido oleico (60,30\%) e o linoleico (21,53\%), que são mais estáveis à oxidação que o ácido linolênico (Lima et al., 2004).

Os resultados obtidos com a adição de BHT ao FCC são pouco conclusivos quanto à efetividade do antioxidante em estabilizar o processo oxidativo neste subproduto. Esta situação pode ser explicada, em parte, pela menor eficiência do antioxidante em proteger a gordura quando adicionado ao alimento ou à ração depois de iniciado o processo de oxidação. Conforme os resultados obtidos, o FCC apresentava indícios de peroxidação lipídica logo após o processamento.

No ensaio de desempenho com frangos de corte, a temperatura média calculada no galpão durante o experimento foi de $28,77^{\circ} \mathrm{C}$, a média das mínimas de $26,84 \pm 1,54^{\circ} \mathrm{C}$ e a média das máximas, de $30,70 \pm 1,28^{\circ} \mathrm{C}$. No período, o valor médio da umidade relativa do ar foi de $62,75 \pm 13,3 \%$.
O consumo de ração, o ganho de peso e a conversão alimentar dos frangos alimentados com as rações contendo FCC não tratado com BHT (controle) não diferiu daqueles obtidos com as rações com FCC tratado com antioxidante em vários tempos de armazenamento (Tabela 3).

O consumo voluntário de alimento pelas aves pode ser influenciado por diversos fatores, entre eles, o nível de energia (Leeson \& Summers, 2001) e a palatabilidade da ração. A lipoperoxidação diminui o valor energético do alimento, em decorrência da destruição dos ácidos graxos (Engberg et al., 1996), e a presença de algumas substâncias formadas durante o processo oxidativo como aldeídos, cetonas, alcoóis, hidrocarbonetos e ácidos causa odor e sabor desagradáveis aos alimentos, diminuindo a palatabilidade da ração e piorando o consumo pelos animais (Racanicci et al., 2004).

Considerando que as rações experimentais foram formuladas para serem isocalóricas (Tabela 1), o fato de o consumo de ração não ter diferido significativamente entre as aves indica que o valor energético e a palatabilidade das rações não foram afetados pelos índices de peroxidação dos FCC tratados ou do não tratado com BHT. Com a adição de 15\% de FCC o nível de peróxidos nas rações experimentais variou de 0,254 a 0,338 meq/kg de ração.

Lin et al. (1989) e Engberg et al. (1996) não observaram alterações no consumo quando rações oxidadas, com índices de peroxidação de 22 e $17 \mathrm{meq} / \mathrm{kg}$, respectivamente, foram fornecidas aos frangos de corte a partir de 10 dias de idade.

Por outro lado, Wang et al. (1997) constataram que frangos alimentados desde o primeiro dia com rações contendo óleo em processo avançado de peroxidação (índice de peroxidação $\geq 11 \mathrm{meq} / \mathrm{kg}$ ) apresentaram aos 49 dias de idade redução no consumo em relação àqueles que 
Tabela 3 -Desempenho de frangos de corte alimentados com rações contendo farelo de castanha de caju, tratado ou não com BHT durante o armazenamento

\begin{tabular}{|c|c|c|c|c|c|c|c|}
\hline & \multirow[t]{2}{*}{ Sem BHT } & \multicolumn{4}{|c|}{ Tempo de armazenamento (dias) } & \multirow[b]{2}{*}{ Média } & \multirow[b]{2}{*}{$\mathrm{CV}(\%)$} \\
\hline & & 0 & 7 & 14 & 21 & & \\
\hline \multicolumn{8}{|c|}{ Período inicial (1 a 21 dias de idade) } \\
\hline Consumo de ração $(\mathrm{kg})$ & 1,172 & 1,182 & 1,202 & 1,183 & 1,217 & 1,191 & 4,56 \\
\hline Ganho de peso $(\mathrm{kg})$ & 0,787 & 0,808 & 0,819 & 0,781 & 0,813 & 0,802 & 4,13 \\
\hline Conversão alimentar & 1,49 & 1,46 & 1,47 & 1,52 & 1,50 & 1,49 & 4,44 \\
\hline \multicolumn{8}{|c|}{ Período total ( 1 a 42 dias de idade) } \\
\hline Consumo de ração $(\mathrm{kg})$ & 4,533 & 4,586 & 4,614 & 4,527 & 4,534 & 4,559 & 3,08 \\
\hline $\begin{array}{l}\text { Ganho de peso }(\mathrm{kg}) \\
\text { Conversão alimentar }\end{array}$ & 2,570 & 2,616 & 2,603 & 2,547 & 2,560 & 2,579 & 2,82 \\
\hline $\mathrm{BHT}=$ butil-hidroxitolueno & 1,76 & 1,75 & 1,77 & 1,78 & 1,77 & 1,77 & 1,97 \\
\hline
\end{tabular}

receberam rações com índice de peroxidação $\leq 0,8 \mathrm{meq} / \mathrm{kg}$. Esses pesquisadores também verificaram que a incorporação do antioxidante às rações contendo óleo peroxidado (índice de peroxidação $\geq 11 \mathrm{meq} / \mathrm{kg}$ ) não promoveu aumento na quantidade de alimento ingerido pelas aves.

Racanicci et al. (2000) comprovaram que as rações formuladas com farinha de carne e ossos tratada com BHT somente aos 28 dias de armazenamento proporcionaram pior consumo em comparação àquelas em que a farinha foi tratada nos dias zero, 7, 14 e 21 ou não foi tratada. Entretanto, neste experimento, o momento da adição do antioxidante ao FCC não teve efeito na ingestão de alimento pelos frangos.

Como as rações eram isonutritivas e o consumo de ração não variou entre os níveis de FCC, não houve efeito ( $\mathrm{P}>0,05)$ sobre o ganho de peso das aves (Tabela 3 ). Acerca do efeito do nível de peroxidação das rações sobre o ganho de peso de frangos de corte criados até 7 semanas, Cabel et al. (1988) relataram que o limite máximo de índice de peroxidação tolerado pelas aves era de $4 \mathrm{meq} / \mathrm{kg}$ de ração. Quando o índice de peroxidação da ração ultrapassou esse valor, os autores verificaram piora no crescimento das aves.

Por outro lado,Lin et al. (1989) e Engberg et al. (1996), utilizando rações com valores de peróxidos superiores ao estabelecido por Cabel et al. (1988) na alimentação de frangos de corte de 21 a 49 dias e de 10 a 42 dias de idade, respectivamente, observaram que a oxidação da gordura não foi suficiente para prejudicar o ganho de peso das aves.

Em relação ao momento da adição do antioxidante ao alimento, Hussein \& Kratzer (1982) constataram redução no ganho de peso das aves alimentadas com rações em que o antioxidante foi adicionado ao farelo de arroz já rancificado em comparação àquelas que receberam rações em que o EDTA (ácido etilenodiamino tetra-acético) foi incorporado ao alimento no início do armazenamento. Wang et al. (1997) e Racanicci et al. (2000) também verificaram diminuição no ganho de peso dos frangos com a demora na incorporação do antioxidante ao alimento ou as rações.

Os efeitos da adição de antioxidantes a alimentos ou rações oxidadas sobre a conversão alimentar de frangos de corte têm sido variáveis. Hussein \& Kratzer (1982), Lin et al. (1989) e Engberg et al. (1996) observaram que o consumo de rações oxidadas, tratadas ou não com antioxidante, não afetou esse parâmetro. De acordo com Cabel et al. (1988), a eficiência alimentar das aves aos 21,42e49 dias de idade não difere quando as rações apresentam níveis de peróxidos de, no máximo, $4 \mathrm{meq} / \mathrm{kg}$, porém, acima desse valor, ocorre piora considerável no aproveitamento do alimento por estes animais. Wang et al. (1997) constataram que houve redução na eficiência alimentar de frangosque consumiram rações oxidadas (índice de peroxidação $\geq 11$ $\mathrm{meq} / \mathrm{kg}$ ) somente na fase inicial, e aos 42 dias de idade não foram verificadas diferenças entre os tratamentos.

As características de carcaça dos frangos abatidos aos 42 dias de idade não foram influenciadas $(\mathrm{P}>0,05)$ pelas rações contendo FCC tratado ou não com BHT em diferentes períodos e armazenado por 35 dias (Tabela 4).

Segundo Leeson(1996), o peso relativo da carcaça está fortemente associado à sua composição e esse efeito é mais relacionado ao teor de gordura corporal que à deposição de proteína no músculo. Assim, quando se elevam os níveis energéticos de uma ração, as respostas clássicas são o aumento na porcentagem de gordura da carcaça e diminuição na porcentagem de proteína.

Como as rações eram isonutritivas - com níveis equivalentes de aminoácidos essenciais, principalmente lisina e metionina-e as aves não apresentaram diferenças no consumo de ração e no ganho de peso, a ausência de variação sobre o rendimento de carcaça e de peito já era esperada (Tabela 4). 
O alto nível de peróxidos na gordura hepática e a presença de muitos dos compostos tóxicos formados durante a oxidação podem provocar danos às células epiteliais do fígado (Leeson \& Summers, 2001). Além disso, mudanças severas na composição normal de ácidos graxos do fígado causam transtornos no metabolismo dos lipídios que resultam em alterações no tamanho deste órgão (Bondi, 1988).

Neste trabalho, a ausência de variação no peso médio relativo do fígado das aves alimentadas com rações contendo FCC, tratado ou não com BHT e armazenado por 35 dias, pode ser um indicativo de que os produtos secundários e terciários formados no decorrer do processo oxidativo do FCC não foram suficientes para produzir mudanças no tamanho desse órgão (Tabela 4). Esses resultados corroboram os descritos por Bailey et al. (1996), que não verificaram influência dos níveis de oxidação do óleo testado sobre o peso absoluto do fígado das aves.

A porcentagem de gordura abdominal das aves não foi afetada $(\mathrm{P}>0,05)$ pelas rações contendo FCC armazenado com ou sem antioxidante (Tabela 4).

Alguns pesquisadores demonstraram que o teor de gordura da carcaça das aves pode aumentar quando se elevam os níveis energéticos da ração, fato que resulta de alterações na relação energia:proteína, na densidade energética ou nos tipos de gordura (Leeson, 1996). Dessa forma, o uso de rações experimentais isocalóricas e com níveis de peroxidação equivalentes na alimentação de frangos de corte permitiu a obtenção de aves com valores percentuais de gordura abdominal bastante próximos.

As porcentagens de umidade e extrato etéreo do fígado e da gordura abdominal dos frangos não foram afetadas $(\mathrm{P}>0,05)$ pelos níveis de FCC nem pelo tratamento desse subproduto com BHT (Tabela 5), com exceção da \%EE do fígado das aves que receberam FCC tratado com BHT no dia zero de armazenamento, cujo valor foi menor $(\mathrm{P}<0,05)$ do que o obtido com a ração controle.

Para proteger sua estrutura celular dos efeitos das substâncias tóxicas e do ataque dos radicais livres, o fígado intensifica o metabolismo lipídico pela síntese e resíntese de fosfolipídios, importantes constituintes das lipoproteínas do sistema de membranas, e de ácidos graxos.

Por sua vez, o menor conteúdo de gordura no fígado das aves alimentadas com as rações contendo FCC tratado com BHT no dia zero parece estar associado à ação do antioxidante, que, além de reduzir a presença de produtos tóxicos e de radicais livres na ração, conferiu maior estabilidade à estrutura celular hepática, permitindo a esse órgão a manutenção de sua atividade metabólica normal.

Tratar o FCC com BHT após 21 dias de armazenamento não teve efeito na proteção do fígado, visto que a \%EE neste órgão foi semelhante à obtida com o FCC não tratado. Algumas pesquisas comprovam que a eficiência dos antioxidantes em prevenir a peroxidação da gordura

Tabela 4 - Características de carcaça de frangos de corte alimentados com rações contendo FCC tratado ou não com BHT durante o armazenamento

\begin{tabular}{lcccrrrrr}
\hline Variável (\%) & \multicolumn{7}{c}{ Período de } & \\
\cline { 2 - 6 } & Sem BHT & BHT no dia 0 & BHT no dia 7 & BHT no dia 14 & BHT no dia 21 & Média & CV (\%) \\
\hline Rendimento de carcaça & 72,44 & 72,42 & 72,64 & 72,69 & 72,19 & 72,48 & 1,25 \\
Rendimento de peito & 34,41 & 34,90 & 34,19 & 34,16 & 34,29 & 34,39 & 3,46 \\
Porcentagem de fígado & 2,15 & 2,20 & 2,20 & 2,19 & 2,21 & 2,19 & 7,76 \\
Porcentagem de gordura abdominal & 2,28 & 1,97 & 2,21 & 2,02 & 2,37 & 2,17 & 19,69 \\
\hline
\end{tabular}

Tabela 5 - Porcentagem de umidade e extrato etéreo do fígado e da gordura abdominal de frangos de corte alimentados com rações contendo farelo de castanha de caju tratado ou não com BHT durante o armazenamento

\begin{tabular}{|c|c|c|c|c|}
\hline & \multicolumn{4}{|c|}{ Variável $(\%)^{1}$} \\
\hline & Umidade & $\mathrm{EE}$ & Umidade & $\mathrm{EE}$ \\
\hline Sem BHT & 74,82 & 3,47 & 16,92 & 81,35 \\
\hline Com adição de BHT no dia zero & 74,72 & $2,89 *$ & 15,53 & 82,92 \\
\hline Com adição de BHT no dia 21 & 74,36 & 3,05 & 15,15 & 83,78 \\
\hline
\end{tabular}

BHT = butil-hidroxitolueno.

${ }^{1}$ Em relação a matéria natural.

* Diferente em relação ao controle pelo teste Dunnet $(\mathrm{P}<0,05)$. 
depende, em grande parte, da incorporação desse aditivo ao alimento ou à ração antes de ter início o processo oxidativo (Araújo, 1999).

Embora o aumento gradativo da oxidação lipídica, sinalizada pelo índice de peróxidos determinado durante o armazenamento do FCC, não tenha prejudicado o desempenho dos frangos de corte (Tabela 3), os resultados obtidos para \%EE do fígado evidenciou a importância da oxidação no metabolismo destas aves, visto que o fígado é o principal órgão responsável pelo metabolismo geral dos animais.

Poucos trabalhos têm relacionado o efeito da alimentação sobre a composição química da gordura corporal das aves. Provavelmente, o fato de o organismo manter praticamente invariável a composição química percentual dos adipócitos favoreça a não- variação no conteúdo de extrato etéreo ou de outro constituinte da gordura.

\section{Conclusões}

A adição de antioxidante não é efetiva no controle da rancidez oxidativa. A inclusão de 15\% de farelo de castanha de caju armazenado durante 35 dias sem antioxidante na ração não influencia o desempenho e as características de carcaça de frangos de corte. Entretanto, o metabolismo lipídico no fígado das aves torna-se mais intenso, como resultado do aumento no teor de extrato etéreo.

\section{Literatura Citada}

ASSOCIATION OF OFFICIAL ANALYTICAL CHEMISTS AOAC. Official methods of analysis. 15.ed. Arlington: 1990. 1298p.

ARAÚJO, J.M.A. Química de alimentos: teoria e prática. 2.ed. Viçosa, MG: Editora UFV, 1999. 416p.

BAILEY, C.A.; SRINIVASAN, L.J.; MCGEACHIN, R.B. The effect of ethoxyquim on tissue peroxidation and immune status of single comb white leghorn cockerels. Poultry Science, v.75, n.9, p.1109-1112, 1996.

BONDI, A.A. Animal nutrition. Zaragoza: Acribia, 1988. 546p. CABEL, M.C.; WALDROUP, W.; SHERMER, W.D. et al. Effects of ethoxyquin feed preservative and peroxide level on broiler performance. Poultry Science, v.67, n.12, p.1725-1730, 1988.

EMPRESA BRASILEIRA DE PESQUISA E AGROPECUÁRIA EMBRAPA. Tabelas de composição química e valores energéticos de alimentos para suínos e aves. 3.ed. Concórdia: Embrapa CNPSA, 1991. 97p. (Documentos, 19).

ENGBERG, R.M.; LAURIDSEN, C.; JENSEN, S.K. et al. Inclusion of oxidized vegetable oil in broiler diets. Its influence on nutrient balance and on oxidative status of broilers. Poultry Science, v.75, n.8, p.1003-1011, 1996.

FISCHER, G.; BERMUDEZ, V.L.; SIQUEIRA, E.B. et al. Peroxidação em amostras de milho, protegidas ou não por etoxiquim. Ciência Animal Brasileira, v.6, n.4, p.227-232, 2005.

HUSSEIN, A.S.; KRATZER, F.H. Effect of rancidity on the feeding value of rice bran for chickens. Poultry Science, v.61, n.11, p.2450-2455, 1982.

LEESON, S. Programas de alimentación para ponedoras y broilers In: CURSO DE ESPECIALIZACIÓN FUNDACIÓN ESPAÑOLA PARA EL DESARROLLO DE LA NUTRICIÓN ANIMAL, 12. 1996, Madrid. Apostila... Madrid: Fundación Española para el Desarrollo de la Nutrición Animal, 1996. p.201-216.

LEESON, S.; SUMMERS, J.D. Nutrition of the chicken. 4.ed Guelph: University Books, 2001. 591p.

LIMA, A.C.; GARCÍA, N.H.P.; LIMA, J.R. Obtenção e caracterização dos principais produtos do caju. Boletim do Centro de Pesquisa de Processamento de Alimentos, v.22, n.1, p.133-144, 2004.

LIN, C.F.; ASGHAR, A.; GRAY, J.I. et al. Effects of oxidized dietary oil and antioxidant supplementation on broiler growth and meat stability. British Poultry Science, v.30, n.4, p.855-864, 1989.

PIMENTEL, C.R.M. Castanha de caju: produção e consumo internacional. Fortaleza: EMBRAPA-CNPCa, 1992. 18p.

PINHEIRO, M.J.P.; BEZERRA NETO, F.; GALVÃO, R.J.D. et al. Película da amêndoa da castanha de caju na ração de suínos em terminação. Caatinga, v.13, n.1/2, p.53-58, 2000.

RACANICCI, A.M.C.; MENTEN, J.F.M.; IAFIGLIOLA, M.C. et al. Efeito da adição do antioxidante BHT e do armazenamento sobre a qualidade da farinha de carne e ossos para frangos de corte. Revista Brasileira de Ciência Avícola, v.2, n.2, p.155-161, 2000.

RACANICCI, A.M.C.; MENTEN, J.F.M.; REGITANO-D'ARCE, M.A.B. et al. Oxidação lipídica do óleo de vísceras de aves reduz o seu conteúdo de energia metabolizável para frangos de corte na fase de crescimento. Revista Brasileira de Zootecnia, v.33, n.4, p.919-923, 2004.

ROSTAGNO, H.S.; ALBINO, L.F.T.; DONZELE, J.L. et al. Tabelas brasileiras para aves e suínos - composição de alimentos e exigências nutricionais. Viçosa, MG: Suprema, 2000. 141p.

SILVA, D.J.; QUEIROZ, A.C. Análise de alimentos: métodos químicos e biológicos. 3.ed. Viçosa, MG: Universidade Federal de Viçosa, 2002. 165p.

SILVA, Y.L.; PEIXOTO, R.R.; PEIXOTO, C.R. Efeito da rancidez no valor nutricional de farelo de arroz com alto teor de gordura para poedeiras. Revista da Sociedade Brasileira de Zootecnia v.19, n.1, p.23-30, 1990.

STATISTICAL ANALYSIS SYSTEM - SAS. SAS user's guide: statistics. Version 8. 2.ed. Cary: SAS Institute, 2000. (CD-ROM).

WANG, S.Y.; BOTTJE, W.; MAYNARD, P. et al. Effects of Santoquim and oxidized fat on liver and intestinal glutatione in broilers. Poultry Science, v.76, n.7, p.961-967, 1997. 